\title{
Enhancing Toughness and Reducing Volumetric Shrinkage for Bis-GMA/TEGDMA Resin Systems by Using Hyperbranched Thiol Oligomer HMDI-6SH
}

\author{
Biao Yu ${ }^{1,2}$, Jingwei He ${ }^{1,3}$, Sufyan Garoushi ${ }^{1}$ (D), Pekka K. Vallittu ${ }^{1}$ and Lippo Lassila ${ }^{1, *}$ \\ 1 Department of Biomaterials Science and Turku Clinical Biomaterials Center-TCBC, Institute of Dentistry, \\ University of Turku, 20520 Turku, Finland; y.biao@lingnan.edu.cn (B.Y.); msjwhe@scut.edu.cn (J.H.); \\ sufgar@utu.fi (S.G.); pekval@utu.fi (P.K.V.) \\ 2 School of Chemistry and Chemical Engineering, Lingnan Normal University, Zhanjiang 524048, China \\ 3 College of Materials Science and Engineering, South China University of Technology, \\ Guangzhou 510642, China \\ * Correspondence: liplas@utu.fi
}

check for updates

Citation: Yu, B.; He, J.; Garoushi, S.; Vallittu, P.K.; Lassila, L. Enhancing Toughness and Reducing Volumetric Shrinkage for Bis-GMA/TEGDMA Resin Systems by Using Hyperbranched Thiol Oligomer HMDI-6SH. Materials 2021, 14, 2817. https://doi.org/10.3390/

ma14112817

Academic Editor: Federica Bondioli

Received: 28 March 2021

Accepted: 22 May 2021

Published: 25 May 2021

Publisher's Note: MDPI stays neutral with regard to jurisdictional claims in published maps and institutional affiliations.

Copyright: (c) 2021 by the authors. Licensee MDPI, Basel, Switzerland. This article is an open access article distributed under the terms and conditions of the Creative Commons Attribution (CC BY) license (https:/ / creativecommons.org/licenses/by/ $4.0 /)$.

\begin{abstract}
In order to improve the toughness and reduce polymerization shrinkage of traditional bisphenol A-glycidyl methacrylate (Bis-GMA)/triethylene glycol dimethacrylate (TEGDMA) based dental resin system, a hyperbranched thiol oligomer (HMDI-6SH) was synthesized via thiol-isocyanate click reaction using pentaerythritol tetra(3-mercaptopropionate (PETA) and dicyclohexylmethane 4,4'-diisocyanate (HMDI) as raw materials. Then HMDI-6SH was mixed with 1,3,5-Triallyl-1,3,5Triazine-2,4,6(1H,3H,5H)-Trione (TTT) to prepare thiol-ene monomer systems, which were added into Bis-GMA/TEGDMA resins with different mass ratio from $10 \mathrm{wt} \%$ to $40 \mathrm{wt} \%$ to serve as anti-shrinking and toughening agent. The physicochemical properties of these thiol-ene-methacrylate ternary resins including functional groups conversion, volumetric shrinkage, flexural properties, water sorption, and water solubility were evaluated. The results showed that the incorporation of HMDI/TTT monomer systems into Bis-GMA/TEGDMA based resin could improve $\mathrm{C}=\mathrm{C}$ double bond conversion from $62.1 \%$ to $82.8 \%$ and reduced volumetric shrinkage from $8.53 \%$ to $4.92 \%$. When the mass fraction of HMDI/TTT monomer systems in the resins was no more than $20 \mathrm{wt} \%$, the flexural strength of the resin was higher or comparable to Bis-GMA/TEGDMA based resins $(p>0.05)$. The toughness (it was measured from the stress-strain curves of three-point bending test) of the resins was improved. Water sorption and water solubility tests showed that the hydrophobicity of resin was enhanced with increasing the content of thioester moiety in resin.
\end{abstract}

Keywords: toughness; volumetric shrinkage; hyperbranched thiol oligomer

\section{Introduction}

Dental resin composites that based on photosensitive dimethacrylate monomers, such as bisphenol A-glycidyl methacrylate (Bis-GMA), triethylene glycol dimethacrylate (TEGDMA), and urethane dimethacrylate (UDMA), have been used as dental restorative materials for several decades due to their sufficient mechanical properties, acceptable aesthetics properties, and good bond ability to tooth tissue. Unfortunately, volumetric shrinkage and polymerization shrinkage stress of resin composites lead to restorations marginal microleakage and secondary caries, which reduce the clinical performance of these materials [1,2]. During the photopolymerization process, the distance between monomers is reduced from Van der Waal force $(\sim 4 \AA)$ to covalent bond distance $(\sim 1.5 \AA)$, and the free volume is reduced too. Simultaneously, shrinkage stress occurs when the contraction is obstructed and the material is rigid enough to resist sufficient plastic flow to compensate for the original volume [3]. The factors involved in the development of stress in dental resin composites are complicated. It was found that inorganic fillers, resin matrix, coupling agent, and polymerization process would affect the polymerization shrinkage stress [4]. 
Among these factors, the resin matrix is considered one of the most important factors [3]. The researchers have developed many strategies to reduce volumetric shrinkage and shrinkage stress. For instance, increasing the content of fillers is an easy strategy to reduced volumetric shrinkage and shrinkage stress [5]. The principle of this strategy is that the higher the content of filler, the lower content of the resin matrix prone to shrinkage. However, the flowability of dental resin composites would be reduced too [6]. Similarly, the increasing molecular weight of monomers to reduce the number of photo-activated groups per molecular is a useful strategy to reduce volumetric shrinkage and shrinkage stress. Still, the viscosity of these monomers would also be increased with high molecular we1ight [7].

Ring-open monomers such as epoxy-functionalized siloxanes [8], spiro orthocarbonates $[9,10]$, cyclic ketene acetals [11], and vinylcyclopropanes [12,13] are usually used as anti-shrinkage agents in dental resins to reduce volumetric shrinkage and shrinkage stress. The mechanism is that they can undergo cation or radical ring open polymerization wherein bonds are broken for each new bond formed. The broken bonds can result in volume expansion to counter the volume contraction when the new bond formed [14].

Different from dimethacrylate based resins, the polymerization of thiol-ene based resins is the step-growth mechanism, resulting in more homogeneous polymeric network formation and high monomer conversion, delayed gel point, and lower polymerization shrinkage and shrinkage stress [15]. Bowman's group firstly reported thiol-ene resins used as dental restorative materials in 2005 [16]. They found that the oligomers of thiol-ene resins had lower volumetric shrinkage and shrinkage stress than Bis-GMA/TEGDMA resin systems, while mechanical properties and glass transition temperature needed to be improved. Subsequently, they incorporated thiol-ene mixture as diluents into conventional dimethacrylate resins to prepare thiol-ene-methacryalte ternary resins. It was found that shrinkage stress reduction while maintaining equivalent flexural modulus $[17,18]$. They also prepared that ester-free thiol-ene dental restorative materials, and found that the polymerization shrinkage stress and water uptake were dramatically reduced, and the toughness of materials was increased [14,19]. He et al. [20] synthesized a novel fluorinated allyl ether and mixed it with pentaerythritol tetra (3-mercaptopropionate) (PETMA) at a molar ratio of 1:1 to form a new thiol-ene resin system. They incorporated these thiol-ene monomer systems into Bis-GMA/TEGDMA resins and found that volumetric shrinkage and shrinkage stress, as well as water sorption and solubility, reduced.

Hyperbranched and dendritic molecules are special topology structure molecules with a central core, a high molecular weight, and many end groups. They have lower viscosity with similar molecular weight compared to their linear analogous counterpart [21]. It is beneficial to reduce volumetric shrinkage and shrinkage stress $[22,23]$ by adding these monomers into dental resins to reduce the content of $\mathrm{C}=\mathrm{C}$ double bonds in resin without increasing viscosity. Some researchers have reported that the incorporation of methacrylate functional end groups hyperbranched or dendritic oligomers into dimethacrylate resins systems to reduce polymerization shrinkage. In our previous study, we have synthesized a dendritic methacrylate oligomer G-IEMA [24]. By adding this dendritic oligomer into UDMA/TEGDMA resin systems, the volumetric shrinkage was reduced with the increasing G-IEMA content in the resin. However, the synthesis process of these dendritic monomers is always tedious and expensive.

Herein, a hyperbranched thiol oligomer was synthesized by thiol-isocyanate click reaction and incorporated into Bis-GMA/TEGDMA based resin with the aim of reducing volumetric shrinkage due to thiol-ene step-growth mechanism and reducing methacrylate group concentrate on in the resin. The physicochemical properties such as mechanical properties, monomer conversion, water solubility, and water sorption were also investigated. 


\section{Materials and Methods}

\subsection{Materials}

2,2-bis [4-(2-hydroxy-3-methacryloyloxypropoxy)phenyl]propane (Bis-GMA), triethylene glycol dimethacrylate (TEGDMA), and Pentaerythritol tetra(3-mercaptopropionate) (PETMP) were purchased from Sigma-Aldrich (Shanghai) Trading Co., Ltd. Shanghai, China. Dicyclohexylmethane 4, $4^{\prime}$-diisocyanate (HMDI), Phloroglucinol (TPX) were obtained from Beijing InnoChem Science \& Technology Co., Ltd. Beijing, China. 1,3,5-Triallyl-1,3,5Triazine-2,4,6(1H,3H,5H)-Trione (TTT), Camphorquinone (CQ), Triethylamine $\left(\mathrm{Et}_{3} \mathrm{~N}\right)$ and 2-(Dimethylamino)ethyl methacrylate (DMAEMA) were purchased from Shanghai Titan Scientific Co., Ltd. Shanghai, China. All chemicals were used without further purification.

\subsection{Synthesis of Hyperbranched Thiol Oligomer HMDI-6SH}

The synthesis route of hyperbranched thiol oligomer HMDI-6SH was shown in Figure 1. $400 \mathrm{~mL}$ of Dichloromethane (DCM) was added into a $1000 \mathrm{~mL}$ three-necked round-bottomed flask equipped with a teflon-coated magnetic stir bar, and then PETA (76.64 g, $152.47 \mathrm{mmol}, 2.00$ equiv.) and $\mathrm{Et}_{3} \mathrm{~N}(0.077 \mathrm{~g}, 0.76 \mathrm{mmol}, 0.01$ equiv.) were added into the flask and dissolved in DCM under nitrogen atmosphere. Afterwards, HMDI ( $20.00 \mathrm{~g}, 76.23 \mathrm{mmol}, 1.00$ equiv.) dissolved in $20 \mathrm{~mL}$ of DCM was adding into the mixture dropwise for $30 \mathrm{~min}$. The reaction mixture was stirred at room temperature and monitored by FT-IR spectrum. It was completed until the peak of -NCO groups at $2230 \mathrm{~cm}^{-1}$ disappeared. After completing the reaction, DCM was removed on a rotary evaporator under vacuum, and the crude product was precipitated using petroleum ether for three times to remove $\mathrm{Et}_{3} \mathrm{~N}$. After removing the solvent under vacuum, the product was obtained as a colourless oil with a yield of $95 \%$. The chemical structure of the thiol oligomer was characterized by FT-IR spectrophotometer ((Nicolet 6700, Thermo Fisher Scientific, Madison, WI, USA, $\mathrm{KBr}$, film) and proton nuclear magnetic resonance ( ${ }^{1} \mathrm{H}$ NMR) (AVANCE $400 \mathrm{MHz}$, Bruker, Berlin, Germany, $\mathrm{CDCl}_{3}, 400 \mathrm{MHz}$ ). The average number of molecular weights (Mn) and the polydispersity of index (PDI) was measured by gel permeation chromatography (GPC) (PL-GPC50, Agilent, Santa Clara, CA, USA), equipped with a low-angle laser light scattering (LALLS) detector. THF was used as the mobile phase at a flow rate of $1 \mathrm{~mL} / \mathrm{min}$ at $30^{\circ} \mathrm{C}$.

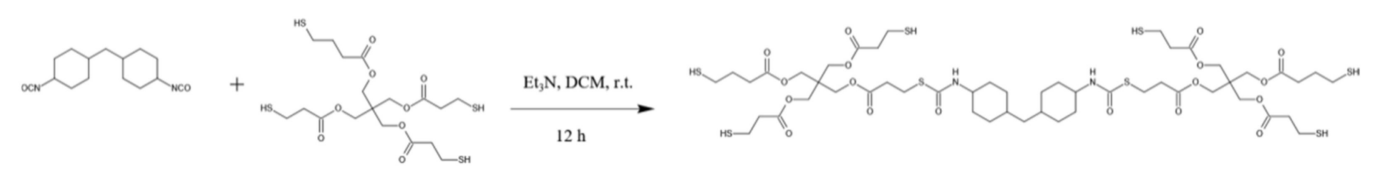

Figure 1. Synthesis route of hyperbranched thiol oligomer HMDI-6SH.

FT-IR (neat, KBr): $3455 \mathrm{~cm}^{-1}, 3358 \mathrm{~cm}^{-1}, 2927 \mathrm{~cm}^{-1}, 2853 \mathrm{~cm}^{-1}, 2567 \mathrm{~cm}^{-1}, 1738 \mathrm{~cm}^{-1}$, $1671 \mathrm{~cm}^{-1}, 1509 \mathrm{~cm}^{-1}, 1469 \mathrm{~cm}^{-1}, 1389 \mathrm{~cm}^{-1}, 1354 \mathrm{~cm}^{-1}, 1248 \mathrm{~cm}^{-1}, 1196 \mathrm{~cm}^{-1}, 1152 \mathrm{~cm}^{-1}$, $1051 \mathrm{~cm}^{-1}, 935 \mathrm{~cm}^{-1} .{ }^{1} \mathrm{H}$ NMR (400 MHz, Chloroform-d): $\delta 5.33$ (s, 1H), 4.48-3.98 (m), 3.25-2.88 (m), 2.73-2.64 (m), 1.93-1.48 (m), 1.37-0.81 (m). Mn: 5530, PDI: 1.83.

\subsection{Preparation of Resin Systems}

The synthesized thiol oligomer HDMI-6SH were mixed with $(1 \mathrm{H}, 3 \mathrm{H}, 5 \mathrm{H})$-Triallyl1,3,5-Triazine-2,4,6(1H,3H,5H)-Trione (TTT) (The mole ratio of -SH groups in HMDI and $\mathrm{C}=\mathrm{C}$ groups in TTT was kept at 1:1). Then, the thiol-ene mixture was added into BisGMA/TEGDMA resins (Bis-GMA/TEGDMA $60 \mathrm{wt} \% / 40 \mathrm{wt} \%$ ) with a series of mass ratio (10 $\mathrm{wt} \%, 20 \mathrm{wt} \%, 30 \mathrm{wt} \%$, and $40 \mathrm{wt} \%)$. The CQ and DEMEMA were served as photoinitiator and co-initiator, and their mass ratios in resin were both $0.7 \mathrm{wt} \%$. The resins were marked as 10\%HMDI/TTT, $20 \% \mathrm{HMDI} / \mathrm{TTT}, 30 \% \mathrm{HMDI} / \mathrm{TTT}$, and $40 \% \mathrm{HMDI} / \mathrm{TTT}$. Bis-GMA/TEGDMA resin without thiol-ene mixture was used as a control. The chemical structure of monomers, photo-initiator and stabilizer used in this study was shown in Figure 2. Photoactivation procedures were performed using a dental lamp (X-cure, 
Woodpecker, Guilin, China) with an irradiation intensity of $1000 \mathrm{~mW} / \mathrm{cm}^{2}$. The uncured resins were injected into stainless steel mold (size $2 \mathrm{~mm} \times 2 \mathrm{~mm} \times 25 \mathrm{~mm}$ ), which were sandwiched between two glass slides. Both sides were irradiated for $60 \mathrm{~s}$ to ascertain uniform conversions throughout the sample thickness. A total of 18 specimens of each model resins was made for flexural properties $(n=10)$, volumetric shrinkage $(n=3)$, and water sorption and solubility analyses $(n=5)$. The specimens were randomly allocated into test groups.
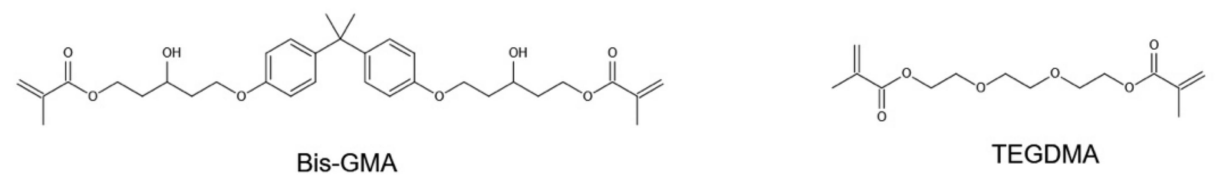

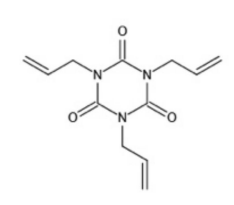

TTT

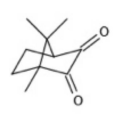

$\mathrm{CQ}$
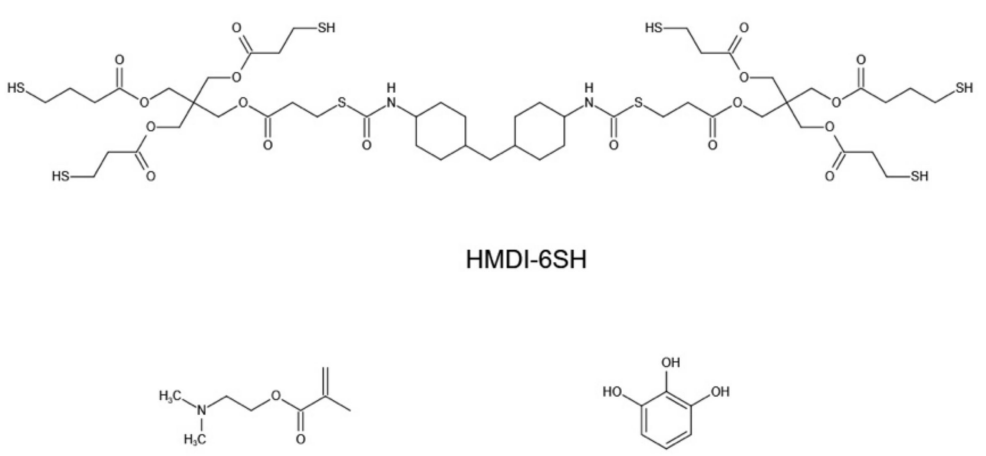

DMAEMA

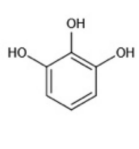

TPX

Figure 2. The chemical structure of monomers, photo-initiator and stabilizer used in this study.

\subsection{Functional Groups Conversion Measurement}

The degree of functional groups conversion (DC\%) during and after the photoinitiation of polymerization was monitored by Fourier transform infrared spectroscopy (FT-IR) (Nicolet 6700, Thermo Fisher Scientific, Waltham, MA, USA). Resin sample was coated on $\mathrm{KBr}$ Pellets to form a very thin film, and the absorbance peak of uncured samples was obtained. Then photo-polymerization of the sample was carried out by irradiation of a dental light source $\left(1000 \mathrm{~mW} / \mathrm{cm}^{2}\right.$, X-cure, Woodpecker, Guilin, China) at room temperature. Spectra during the irradiation process were recorded every $10 \mathrm{~s}$ for $1 \mathrm{~min}$. The DC\% was calculated from the aliphatic $C=C$ peak at $1636 \mathrm{~cm}^{-1}$, thiol group peak at $2530 \mathrm{~cm}^{-1}$ normalized against the benzene $\mathrm{C}=\mathrm{C}$ double bond peak at $1608 \mathrm{~cm}^{-1}$, according to formula (1)

$$
D C \%=\frac{\left(\frac{A_{\text {fun }}}{A_{\text {benzene }}}\right)_{0}-\left(\frac{A_{\text {fun }}}{A_{\text {benzene }}}\right)_{t}}{\left(\frac{A_{\text {fun }}}{A_{\text {benzene }}}\right)_{0}}
$$

where $A_{\text {fun }}$ and $A_{\text {benzene }}$ are the absorbance peak areas of functional groups ( $\mathrm{C}=\mathrm{C}$ double bond groups at $1640 \mathrm{~cm}^{-1}$, thiol groups at $2230 \mathrm{~cm}^{-1}$ ), and benzene at $1608 \mathrm{~cm}^{-1}$, respectively. $\left(\frac{A_{\text {fun }}}{A_{\text {benzene }}}\right)_{0}$ and $\left(\frac{A_{\text {fun }}}{A_{\text {benzene }}}\right)$ are the normalized absorbance of the functional groups at radiation time of 0 and $t$, respectively; $D C(t) \%$ is the conversion of functional groups as a function of radiation time.

\subsection{The Determination of Glass Transition Temperature $\left(T_{g}\right)$}

The glass transition temperature $\left(T_{\mathrm{g}}\right)$ of the cured resins was determined by dynamic mechanical analysis (Q800, TA, New Castle, DE, USA) using an in tensile mode. Bars of $30 \times 10 \times 3 \mathrm{~mm}$ were heated from -30 to $120^{\circ} \mathrm{C}$ at $3 \mathrm{~K} / \mathrm{min}$ under a nitrogen atmosphere, using a frequency of $1 \mathrm{~Hz}$. 


\subsection{Flexural Properties}

Ten specimens with a size of $2 \mathrm{~mm} \times 2 \mathrm{~mm} \times 25 \mathrm{~mm}$ were prepared for every resin formulation. Five specimens were kept dry until the start of testing, and the other five samples were stored in distilled water at $37^{\circ} \mathrm{C}$ until the start of testing (the storage time was as long as the time for water sorption and solubility test). Three points bending test (span $20 \mathrm{~mm}$ ) was carried out to evaluate the flexural strength $(F S)$ and modulus $(F M)$ according to ISO 10477:92 standard with a universal testing machine (Model Z010, Zwick GmbH \& Co. KG, Ulm, Germany) at a cross-head speed of $1.00 \mathrm{~mm} / \mathrm{min}$ [25]. The FS in $\mathrm{MPa}, F M$ in GPa, and toughness (TS) in $\mathrm{KJ} / \mathrm{m}^{2}$ were then calculated as:

$$
\begin{gathered}
F S=\frac{3 p L}{2 b h^{2}} \\
F M=\frac{S L^{3}}{4 b h^{3}} \\
T S=\frac{A}{b h}
\end{gathered}
$$

where $p$ stands for load at fracture $(\mathrm{N}), L$ is the span length $(20 \mathrm{~mm}), b$ and $h$ are the width and thickness of the specimens in $\mathrm{mm}$, respectively.

$S$ is the stiffness $(\mathrm{N} / \mathrm{m}) . \mathrm{S}=\mathrm{F} / \mathrm{d}, d$ is the deflection corresponding to load $\mathrm{F}$ at a point in the straight-line portion of the trace. The FM was also determined from the slope of the initial linear part of stress-strain curve.

$A$ is the area under load-deflection cure and is the energy applied on specimens in Joules (J).

\subsection{Volumetric Shrinkage}

The volumetric shrinkage (VS\%) was measured using the variation of densities before and after polymerization according to Equation (5).

$$
V S \%=\frac{\rho_{\text {polymer }}-\rho_{\text {monomer }}}{\rho_{\text {polymer }}} \times 100 \%
$$

where $\rho_{\text {polymer }}$ was the densities of cured resin and $\rho_{\text {monomer }}$ was the densities of the uncured resins. $\rho_{\text {polymer }}$ and $\rho_{\text {monomer }}$ were measured by densitometer (MDJ-300M, Xiongfa Instrument, Xiamen, China), according to Archimedes's principle. Each resin formulation was measured for three times.

\subsection{Water Sorption and Water Solubility}

To measure water sorption (WS\%) and water solubility (SL\%) of cured resin, the rectangular beam specimens (size $2 \mathrm{~mm} \times 2 \mathrm{~mm} \times 25 \mathrm{~mm}$, five specimens for each resin formulation) used as three-point bending test were prepared. The dry weight $\left(M_{1}\right)$ of specimens was measured by a balance (MDJ-300M, Xiongfa Instrument, Xiamen, China) with an accuracy of $0.1 \mathrm{mg}$.

Then, every specimen was immersed in $30 \mathrm{~mL}$ of distilled water at $37^{\circ} \mathrm{C}$. At a fixed time interval, they were removed out from the water and dried to remove excess water with absorbent paper, re-weighed, and returned to the water. Equilibrium mass $\left(M_{2}\right)$ was obtained until there was no significant change in mass at 30th day immersion.

The specimens were dried at $60{ }^{\circ} \mathrm{C}$ until their mass was constant, and the result was recorded as $\mathrm{M}_{3}$. Water sorption (WS\%) and solubility (SL\%) were then calculated using the following formula.

$$
\begin{aligned}
W S \% & =\frac{M_{2}-M_{1}}{M_{1}} \times 100 \% \\
S L \% & =\frac{M_{1}-M_{3}}{M_{1}} \times 100 \%
\end{aligned}
$$




\subsection{Statistical Analysis}

The experiments results were analyzed using one-way analysis of variance (ANOVA). Multiple pair-wise comparisons were further conducted using Tukey's test with a significance level of 0.05 .

\section{Result and Discussion}

\subsection{Hyperbranched Thiol Oligomer (HMDI-6SH) Synthesis}

Hyperbranched oligomers do not have an accurate chemical structure with polydispersity compared to their dendritic molecules, but their synthesized process is easier than dendritic molecules without a tedious purified process. We synthesized HMDI-6SH using thiol-isocyanate click reaction via one-pot without further purification. Thiol groups can react with isocyanate groups quantitatively with Lewis bases in a dipolar solvent such as dimethyl sulfoxide (DMSO) or acetonitrile (ACN). After the reaction competition, the peak at $2230 \mathrm{~cm}^{-1}$ attributed to -NCO group in FT-IR spectrum was disappeared accompanied with the appearance of -SH group at $2560 \mathrm{~cm}^{-1}$. The chemical structure of HMDI-6SH had been confirmed by FT-IR (Figure 3 ) and ${ }^{1} \mathrm{H}-\mathrm{NMR}$ (Figure 4) spectrum. The average number of molecular weight (Mn) of HMDI-6SH was 5530 and PDI was 1.83 (Figure 5).

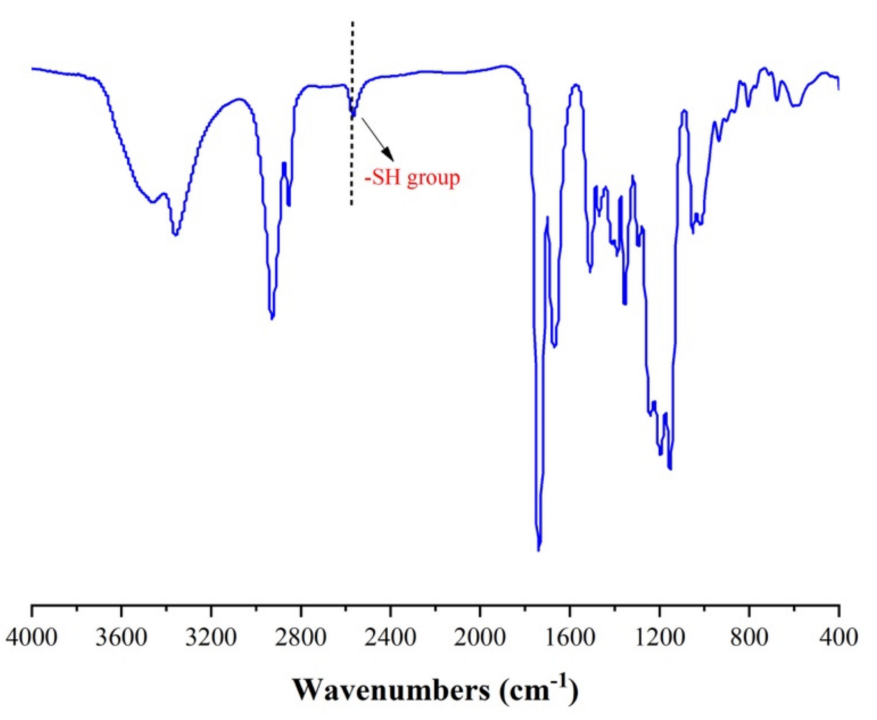

Figure 3. FT-IR spectrum of hyperbranched thiol oligomer HMDI-6SH.
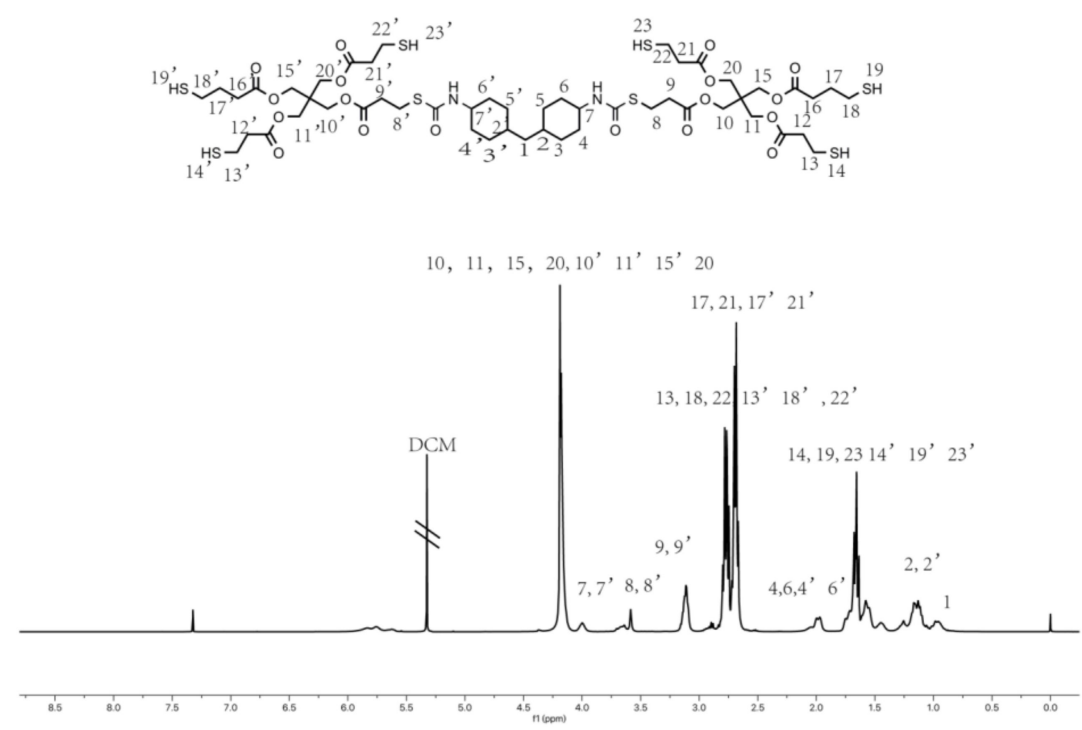

Figure $4 .{ }^{1} \mathrm{H}-\mathrm{NMR}$ spectrum of hyperbranched thiol oligomer HMDI-6SH. 


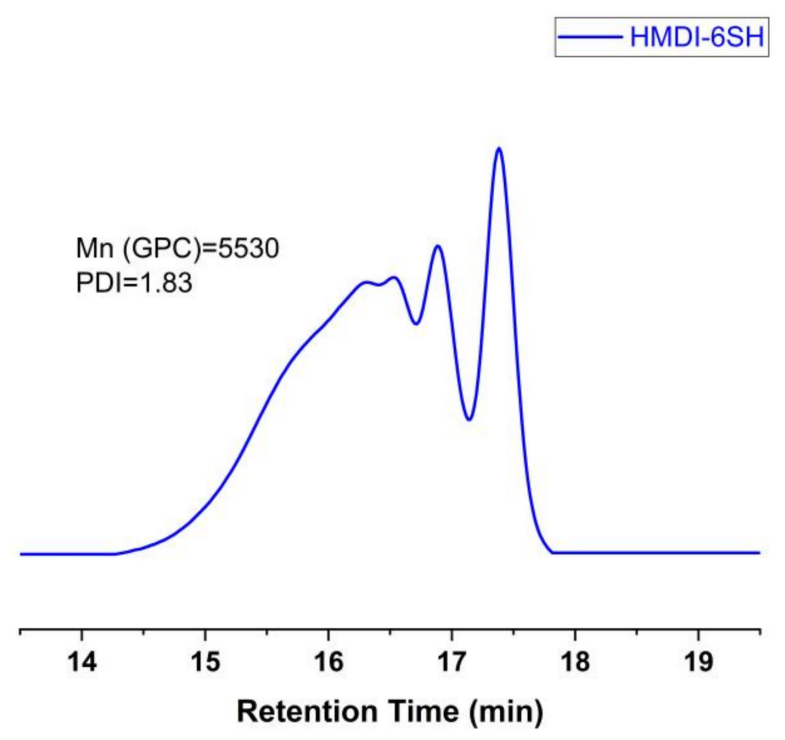

Figure 5. GPC traces of HMDI-6SH.

\subsection{Degree of Conversion}

High final functional groups conversion for dental monomers was beneficial to the long-term material properties of dental resin systems [26]. The degree of functional groups conversion was usually monitored by real-time FTIR technology. Figure 6 showed the degree of conversion (DC\%) versus irradiated time curves of methacrylate and thiol groups. It could be observed that the DC\% for these two functional groups increased obviously for the first $20 \mathrm{~s}$ irradiation time, and the variation became slower after $20 \mathrm{~s}$.

(a)

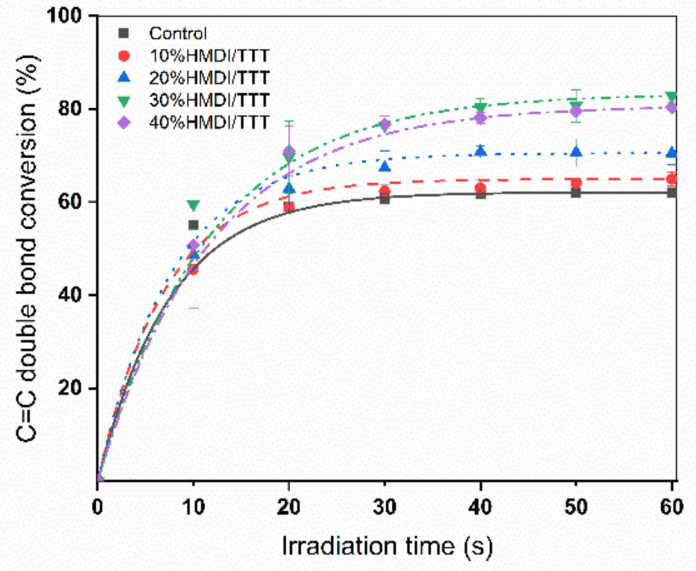

(b)

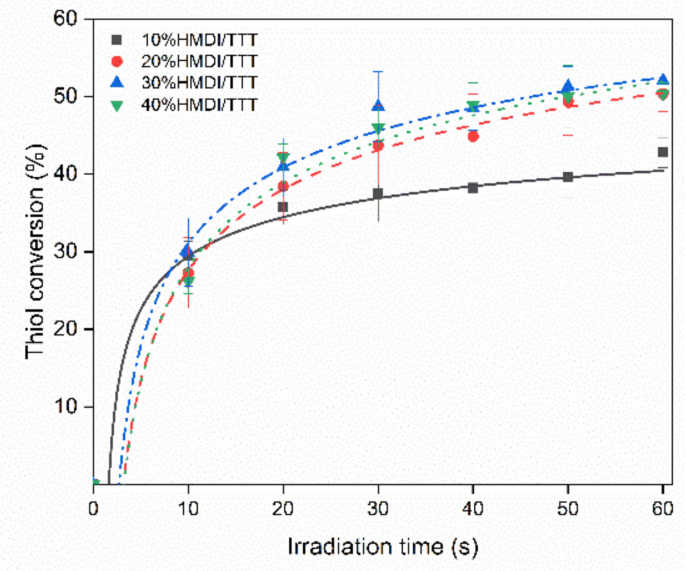

Figure 6. The degree of conversion of methacrylate (a) and thiol groups (b).

As shown in Table 1, DC \% at $60 \mathrm{~s}$ irradiation time for methacrylate increased with the increasing of thiol-ene content in thiol-ene-methacryalte ternary resin system. A similar tendency was also observed for thiol conversion. It was indicated that HDMI/TTT thiolene resin system enhanced polymerization rate and significantly increased final function group conversion. 
Table 1. The degree of conversion $\mathrm{C}=\mathrm{C}$ double bond and thiol group at $60 \mathrm{~s}$.

\begin{tabular}{ccc}
\hline Resins & $\begin{array}{c}\text { C=C Double Bond } \\
\text { Conversion at 60 s (\%) }\end{array}$ & $\begin{array}{c}\text { Thiol (-SH) Conversion } \\
\text { at 60 s (\%) }\end{array}$ \\
\hline Control & $62.1 \pm 1.1^{\mathrm{a}}$ & - \\
10\%HMDI-6SH/TTT & $63.8 \pm 1.8^{\mathrm{a}}$ & $42.8 \pm 2.0^{\mathrm{a}}$ \\
20\%HMDI-6SH/TTT & $68.1 \pm 2.0^{\mathrm{b}}$ & $50.4 \pm 2.3^{\mathrm{b}}$ \\
$30 \% H M D I-6 S H / T T T$ & $82.8 \pm 1.5^{\mathrm{c}}$ & $54.1 \pm 1.4^{\mathrm{b}}$ \\
$40 \%$ HMDI-6SH/TTT & $80.1 \pm 1.9^{\mathrm{c}}$ & $50.3 \pm 1.4^{\mathrm{b}}$ \\
\hline
\end{tabular}

a The same lower case letters indicated no statistical differences within a column (Tukey's test, $p=0.05$ ).

\subsection{Volumetric Shrinkage}

As seen from Table 2, after adding $10 \mathrm{wt} \%$ to $40 \mathrm{wt} \%$ of HMDI-6SH/TTT resin system into Bis-GMA/TEGDMA system, the volumetric shrinkage of dental resin was decreased from $8.52 \%$ to $4.92 \%$. According to statistical analysis, the volumetric shrinkage of 10\%HMDI/TTT systems had no statistical difference between 20\%HMDI/TTT and 30\% HMDI/TTT systems $(p>0.05)$, but lower than control $(p<0.05)$, and higher than $40 \%$ HMDI/TTT resin systems $(p<0.05)$.

Table 2. The volumetric shrinkage of the unfilled resins.

\begin{tabular}{cc}
\hline Resins & Volumetric Shrinkage (\%) \\
\hline Control & $8.53 \pm 0.22^{\mathrm{a}}$ \\
10\%HMDI-6SH/TTT & $6.59 \pm 0.25^{\mathrm{b}}$ \\
20\%HMDI-6SH/TTT & $6.72 \pm 0.23^{\mathrm{b}}$ \\
$30 \%$ HMDI-6SH/TTT & $6.50 \pm 0.26^{\mathrm{b}}$ \\
$40 \%$ HMDI-6SH/TTT & $4.92 \pm 0.13^{\mathrm{c}}$ \\
\hline
\end{tabular}

a The same lower case letters indicated no statistical differences within a column (Tukey's test, $p=0.05$ ).

\subsection{Water Sorption and Water Solubility}

The chemical degradation of dental resin would be accelerated by water through the oxidation process and hydrolysis [27]. Excessive water sorption and water solubility of dental resin resulted in reduced service lifetime [14]. As shown in Table 3, with the increasing amount of HDMI/TTT resin system, the water sorption of the resin was in a trend of decreasing. Compared with control resin, only $40 \%$ HMDI/TTT had higher water solubility $(p<0.05)$, all the other ternary resin systems had comparable water solubility $(p>0.05)$.

Table 3. Water sorption and water solubility of unfilled resins.

\begin{tabular}{ccc}
\hline Resins & Water Sorption (\%) & Water Solubility (\%) \\
\hline Control & $2.15 \pm 0.09^{\mathrm{a}}$ & $1.33 \pm 0.03^{\mathrm{a}}$ \\
$10 \%$ HMDI-6SH/TTT & $2.05 \pm 0.08^{\mathrm{a}, \mathrm{b}}$ & $1.11 \pm 0.09^{\mathrm{a}}$ \\
$20 \%$ HMDI-6SH/TTT & $1.93 \pm 0.04^{\mathrm{b}, \mathrm{c}}$ & $1.04 \pm 0.11^{\mathrm{a}}$ \\
$30 \%$ HMDI-6SH/TTT & $1.60 \pm 0.09^{\mathrm{d}}$ & $1.29 \pm 0.10^{\mathrm{a}}$ \\
$40 \%$ HMDI-6SH/TTT & $1.41 \pm 0.12^{\mathrm{d}}$ & $1.79 \pm 0.12^{\mathrm{b}}$ \\
\hline
\end{tabular}

a The same lower case letters indicated no statistical differences within a column (Tukey's test, $p=0.05$ ).

\subsection{The Determination of Glass Transition Temperature $\left(T_{g}\right)$}

As shown in Figure 7, the Control group exhibited one broad peak at around $100{ }^{\circ} \mathrm{C}$, suggesting that it was a heterogeneous polymeric network. With the concentration of HDMI-6SH/TTT thiol-ene monomers system increased, the peak of $\tan \delta$ was narrowed, it was attributed to the step-growth reaction process of thiol monomers with methacrylate monomers (Bis-GMA or TEGDMA) and ene monomer (TTT) to obtain the more homogeneous network [28]. Simultaneously, the deceasing tendency of $T_{\mathrm{g}}$ was observed as given in Table 4. It was resulting from the lower crosslink density due to chain 
transfer reaction to thiol from ene monomer to reduce the molecular weight of the polymer and high flexible thioether moieties incorporated into the polymer network [29].

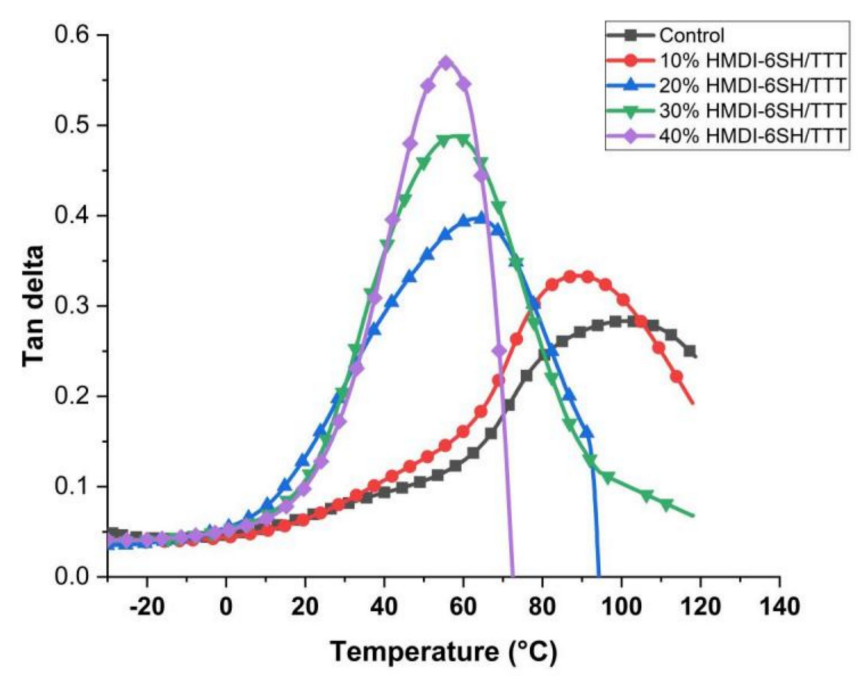

Figure 7. The $\tan \delta$ versus temperature curves of the cured resin systems.

Table 4. The glass transition temperature $\left(T_{\mathrm{g}}\right)$ of the cured resins systems determined by DMA.

\begin{tabular}{cc}
\hline Resins & $\boldsymbol{T}_{\mathbf{g}}\left({ }^{\circ} \mathbf{C}\right)$ \\
\hline Control & 100 \\
10\% HMDI-6SH/TTT & 89 \\
20\% HMDI-6SH/TTT & 63 \\
30\% HMDI-6SH/TTT & 57 \\
$40 \%$ HMDI-6SH/TTT & 55 \\
\hline
\end{tabular}

\subsection{Flexural Properties}

The results of flexural strength (FS), flexural modulus (FM), and toughness of dental resins were shown in Table 5, It was shown that FS of 10\% HMDI-6SH/TTT resin and 20\% HMDI-6SH/TTT resin was equivalent to that of control resin $(p>0.05)$ and higher than those of 30\% HMDI/TTT resin and 40\% HMDI/TTT resin $(p<0.05)$. However, when the content of HMDI-6SH/TTT monomer systems in resins was exceed $10 \mathrm{wt} \%$, the FM of resin decreased from $2.52 \mathrm{GPa}(10 \% \mathrm{HDMI} / \mathrm{TTT})$ to $0.39 \mathrm{GPa}(40 \% \mathrm{HDMI} / \mathrm{TTT})(p<0.05)$. It was in good agreement with several previous reports that incorporation of thiol-ene resin into methacrylate resin would decrease FS and FM $[16,17,20,30]$.

Table 5. The flexural strength (FS), flexural modulus (FM) and toughness of unfilled resins before and after water immersion.

\begin{tabular}{|c|c|c|c|c|c|c|}
\hline \multirow{2}{*}{ Resins } & \multicolumn{3}{|c|}{ Before Water Immersion } & \multicolumn{3}{|c|}{ After Water Immersion } \\
\hline & FS (MPa) & FM (GPa) & TS $\left(\mathrm{KJ} / \mathrm{m}^{2}\right)$ & FS (MPa) & FM (GPa) & $\mathrm{TS}\left(\mathrm{KJ} / \mathrm{m}^{2}\right)$ \\
\hline Control & $92.5 \pm 5.9^{\mathrm{a}, \mathrm{A}}$ & $2.53 \pm 0.23^{\mathrm{a}, \mathrm{A}}$ & $4.76 \pm 0.92^{\mathrm{a}, \mathrm{A}}$ & $76.7 \pm 8.7^{a, B}$ & $2.44 \pm 0.02^{\mathrm{a}, \mathrm{A}}$ & $3.40 \pm 0.41^{\mathrm{a}, \mathrm{B}}$ \\
\hline 10\%HMDI-6SH/TTT & $93.4 \pm 4.0^{\mathrm{a}, \mathrm{A}}$ & $2.52 \pm 0.25^{\mathrm{a}, \mathrm{A}}$ & $5.46 \pm 0.31^{\mathrm{a}, \mathrm{A}}$ & $88.8 \pm 2.9 \mathrm{~b}, \mathrm{~A}$ & $2.54 \pm 0.16^{\mathrm{a}, \mathrm{A}}$ & $5.07 \pm 0.59 \mathrm{~b}, \mathrm{~A}$ \\
\hline 20\%HMD-6SH/TTT & $91.4 \pm 2.0^{\mathrm{a}, \mathrm{A}}$ & $2.20 \pm 0.05^{\mathrm{b}, \mathrm{A}}$ & $9.75 \pm 0.97 \mathrm{~b}, \mathrm{~A}$ & $76.0 \pm 5.3^{\mathrm{a}, \mathrm{B}}$ & $1.90 \pm 0.25^{\mathrm{b}, \mathrm{B}}$ & $8.09 \pm 1.32^{\mathrm{c}, \mathrm{A}}$ \\
\hline 30\%HMDI-6SH/TTT & $79.3 \pm 5.9 \mathrm{~b}, \mathrm{~A}$ & $1.95 \pm 0.18^{\mathrm{c}, \mathrm{A}}$ & $10.52 \pm 1.93^{\mathrm{b}, \mathrm{A}}$ & $58.9 \pm 3.5^{c, B}$ & $1.35 \pm 0.13^{\mathrm{c}, \mathrm{B}}$ & $7.96 \pm 1.68^{\mathrm{c}, \mathrm{A}}$ \\
\hline 40\%HMDI-6SH/TTT & $21.4 \pm 1.2^{\mathrm{c}, \mathrm{A}}$ & $0.39 \pm 0.06^{\mathrm{d}, \mathrm{A}}$ & $8.22 \pm 1.29 \mathrm{~b}, \mathrm{~A}$ & $17.7 \pm 4.0^{\mathrm{d}, \mathrm{A}}$ & $0.26 \pm 0.09^{\mathrm{d}, A}$ & $5.90 \pm 1.24^{b, \mathrm{~B}}$ \\
\hline
\end{tabular}

${ }^{\text {a }}$ The same lower case letters indicated no statistical differences within a column (Tukey's test, $p=0.05$ ). ${ }^{\mathrm{A}}$ The same upper case letters indicated no statistical differences between the same property before and after water immersion (Tukey's test, $p=0.05$ ).

Toughness of the resin was increased obviously after the incorporation HDMI-6SH/TTT resin $(p<0.05)$. The FS and FM of $20 \%$ HMDI-6SH/TTT resin was comparable to the Control resin $(p>0.05)$, but WF of it was about two times more than control resin $(p<0.05)$, 
which demonstrated that the toughness of resin was increased. Stress/displacement curves as shown in Figure 8a also indicated the remarkable increase in toughness when HDMI$6 \mathrm{SH} / \mathrm{TTT}$ resin system was added into Bis-GMA/TEGDMA resin system.
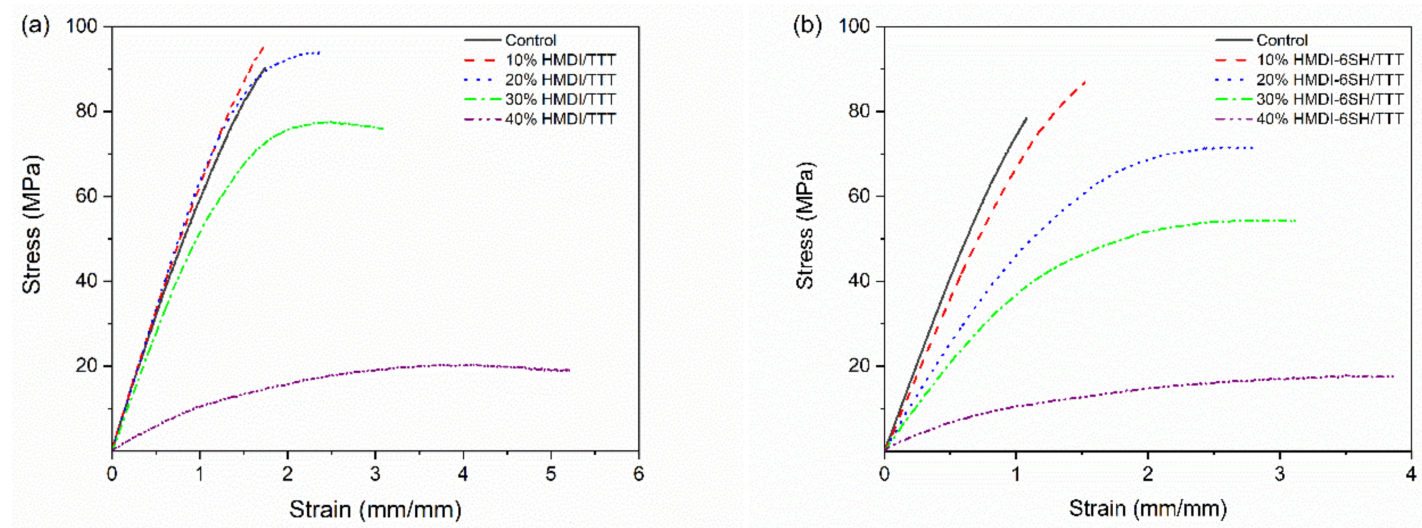

Figure 8. Stress/displacement curves of unfilled resins systems in three-point bending test: (a) before water immersion; (b) after water immersion.

With increasing the content of thiol monomers in thiol-ene-methacrylate ternary system, the molecular weight of the methacrylate oligomers decreased because of increasing the chain transfer rate for the thiol group, which could lead to the reduction of flexural modulus, hardness as well as glass transition temperatures $\left(T_{\mathrm{g}}\right)$ due to the flexibility of polythioethers moieties generated from thiol-ene reaction [31,32]. As a result, the flexibility of the polymer network was increased with the increasing of polythioethers moieties, which allowed the polymer network to absorb more stress generated from flexural tests, leading to the improvement in toughness of resin [25].

\section{Discussion}

In this study, thiol groups conversion ( 50\%) (Table 1) was not achieved as high as expected. To our acknowledge, the thiol group conversion was mainly affected by the structure of ene monomers. Our result was in agreement with Li et al.'s research [29]. Thiol group conversion can be high as $\mathrm{C}=\mathrm{C}$ double bond conversion when thiol monomer copolymerized with allyl ether monomers, divinyl ether monomers, and triallyl triazine monomers expect acrylate monomers. That's because the thiol group conversion was suppressed by the high homopolymerization propensity of methacrylate groups.

After adding HDMI-6SH/TTT resin system into traditional Bis-GMA/TEGDMA resin, the ternary resin would have mainly three types of a chemical reaction during photopolymerization: (i) thiol-methacrylate chain transfer reaction; (ii) thiol-methacrylate and thiol-allyl triazine step-growth propagation; (iii) methacrylate-methacrylate chain propagation. The reaction rate of the thiol-methacrylate chain transfer reaction was higher than the latter two reactions, delaying the gel-point until high functional groups conversion [33]. The results of $\mathrm{DC} \%$ in this study were consistent with previous studies on thiol-ene-methacrylate systems $[14,20]$.

Previous studies have demonstrated that thiol-ene based resin had lower shrinkage than methacrylate-based resin $[16,26]$. With the increase of concentration of HMDI6SH/TTT resin systems, the trendy of volumetric shrinkage of dental resins was decreasing. Although the conversion rate of monomers of thiol-ene-methacrylate ternary resin was higher than methacrylate-based resin, but volumetric shrinkage was still lower than methacrylate based resin, the result was in good agreement with the previous study [16]. The step-growth mechanism of thiol-ene and thiol-methacrylate polymerization led to lower volumetric shrinkage than traditional methacrylate-based resin. On the other hand, hyperbranched oligomers HMDI-6SH with a lower concentration of functional groups and lower free volume might also decrease volumetric shrinkage further [24]. 
The mole ratio of thiol to ene functional groups play an essential role in the physical properties of thiol-ene-methacrylate ternary resins such as flexural properties, volumetric shrinkage, and $T_{\mathrm{g}}$. At low mole ratio of thiol to ene (5 20\%), flexural modulus, and $T_{\mathrm{g}}$ compare to pure methacrylate resins. Simultaneously, the polymerization rate of methacrylate was enhanced [15]. However, at a high mole ratio of thiol to ene functional groups, more chain transfer occurs throughout the network formation leading to reduced methacrylate chain length and lower crosslink density and glass transition temperature while enhancing structure homogeneity and final methacrylate groups conversion [28].

In this study, when the content of HMDI-6SH/TTT thiol-ene reached $40 \mathrm{wt} \%$, the crosslink density of the resin system was reduced due to chain transfer through the network formation leading to lower crosslink density. The polymer chains become looser, and the resin changes from a glassy state to a rubbery state. The dramatical reduction of flexural strength and flexural modulus of $40 \% \mathrm{HDMI}-6 \mathrm{SH} / \mathrm{TTT}$ also confirmed the hypothesis (Table 5). It was the reason why the volumetric shrinkage of $40 \% \mathrm{HDMI}-6 \mathrm{SH} / \mathrm{TTT}$ reduced dramatically compared to other resins systems.

Several factors would influence water uptake value [34]. Among them, the hydrophilicity of the polymer matrix affected the water absorption of resin. Polar functional groups in a polymer matrix, such as hydroxyl groups, which created hydrogen bonds with water, would increase the water sorption [35]. On the contrary, Hydrophobic functional group such as thiol groups or thioether moieties reduced the water sorption of resin [36]. In the present work, there were two hydroxyl groups in one Bis-GMA molecular, so with increasing of HMDI-6SH/TTT thiol-ene system in resin, the content of hydroxyl groups in resin was reduced. At the same time, the content of thiol groups or thioether moieties in resins increased, leading to the enhancement of resin hydrophobicity. As a result, the reducing trendy of water sorption of resins was observed.

The water solubility of dental resins was affected by the type of monomers [37], DC\%, the type of fillers, and fillers concentration [38]. In general, the lower DC\%, the easier for residual monomers leaching out from dental resin. Although the ternary resin system had comparable or higher double bond DC \% than Bis-GMA/TEGDMA based resin as shown in Table 1, their water solubility still had no significant difference, except for $40 \%$ HMDI$6 \mathrm{SH} / \mathrm{TTT}$ resin system, which had the highest water solubility. It should be explained that the molecular weight of the resin was decreased with the increasing chain transfer rate due to increasing the concentration of thiol oligomer HMDI-6SH. Furthermore, the flexibility and free volume of the polymeric network were increased with increasing the content of thioethers moieties and HMDI-6SH, which led to maximation of network expansion, increasing the mobility of residual monomers or oligomers [37].

In order to evaluate the flexural properties of resin in the oral environment, the threepoint bending test specimens were immersed in water at $37^{\circ} \mathrm{C}$ for at least 30 days. As shown in Table 5 and Figure 8b, the decreasing trendy of flexural strength (FS), flexural modulus (FM), and toughness of the resins were observed due to the plasticization effect of water molecules after water immersion, because water molecules penetrated the polymer network [37]. The lower water sorption of the resin that reduces the plasticization effect of water in the polymer matrix was beneficial for keeping flexural properties of dental resin in the oral moist environment [14]. As shown in Table 3, the water sorption value and water solubility value of $10 \% \mathrm{HMDI}-6 \mathrm{SH} / \mathrm{TTT}$ resin system and $20 \% \mathrm{HMDI}-6 \mathrm{SH} / \mathrm{TTT}$ resin system were lower or comparable to Bis-GMA/TEGDMA control and their FS and WF shown higher or equal than Bis-GMA/TEGDMA based control after water immersion. According to the results shown in Table 5, when the content of HMDI-6SH/TTT was not more than $20 \mathrm{wt} \%$ in the ternary resin system, flexural properties after water immersion, water sorption, and solubility were all not influenced negatively. These results indicated that the stability of the resins was not sacrificed after adding a certain amount of HDMI/TTT monomer systems into Bis-GMA/TEGDMA based resin. 


\section{Conclusions}

In Summary, a hyperbranched oligomer HMDI-6SH was synthesized via thiol-isocyanate click reaction without further purification. Its chemical structure was characterized by FTIR and ${ }^{1} \mathrm{H}$ NMR spectrum. The result showed that when the mass ratio of HDMI-6SH/TTT thiol-ene monomers in the resins was not more than $20 \mathrm{wt} \%$, the higher $\mathrm{DC} \%$, higher toughness, lower volumetric shrinkage, lower water sorption, and lower solubility for the resins were obtained. These advantages were a benefit to improve the service life for Bis-GMA/TEGDMA based resins.

With limitation of this study, although the volumetric shrinkage of Bis-GMA/TEGDMA resin systems have been reduced by adding HMDI-6SH/TTT resin system, shrinkage stress of the resins would be investigated in future. The odor of thiol monomers should be considered in the practical applications, some other properties such as biocompatibility should be also studied in future.

Author Contributions: Conceptualization, B.Y. and L.L.; validation, L.L. and P.K.V.; methodology, B.Y.; formal analysis, B.Y.; investigation, S.G.; data curation, B.Y.; writing-original draft preparation, B.Y.; writing-review and editing, J.H. and S.G.; visualization-B.Y.; supervision-L.L. and P.K.V.; project administration, L.L.; funding acquisition, B.Y., J.H., and L.L. All authors have read and agreed to the published version of the manuscript.

Funding: This research was supported by foundation of NATURAL SCIENCE FOUNDATION OF CHINA (grant number 21805125 and 81970974), NATURAL SCIENCE OF LINGNAN NORMAL UNIVERSITY (grant number ZL1609) and the APC was funded by Department of Biomaterials Science and Turku Clinical Biomaterials Center-TCBC.

Institutional Review Board Statement: Not applicable.

Informed Consent Statement: Not applicable.

Data Availability Statement: The data presented in this study are available on request from the corresponding author. The data are not publicly available due to IPR considerations.

Conflicts of Interest: There are no conflicts of interest declared by the authors.

\section{References}

1. Calheiros, F.C.; Sadek, F.T.; Braga, R.R.; Cardoso, P.E.C. Polymerization contraction stress of low-shrinkage composites and its correlation with microleakage in class V restorations. J. Dent. 2004, 32, 407-412. [CrossRef] [PubMed]

2. Versluis, A.; Tantbirojn, D.; Pintado, M.R.; DeLong, R.; Douglas, W.H. Residual shrinkage stress distributions in molars after composite restoration. Dent. Mater. 2004, 20, 554-564. [CrossRef] [PubMed]

3. Davidson, C.L.; Feilzer, A.J. Polymerization shrinkage and polymerization shrinkage stress in polymer-based restoratives. J. Dent. 1997, 25, 435-440. [CrossRef]

4. Braga, R.R.; Ballester, R.Y.; Ferracane, J.L. Factors involved in the development of polymerization shrinkage stress in resincomposites: A systematic review. Dent. Mater. 2005, 21, 962-970. [CrossRef]

5. Gonçalves, F.; Azevedo, C.L.N.; Ferracane, J.L.; Braga, R.R. BisGMA/TEGDMA ratio and filler content effects on shrinkage stress. Dent. Mater. 2011, 27, 520-526. [CrossRef]

6. Labella, R.; Lambrechts, P.; Van Meerbeek, B.; Vanherle, G. Polymerization shrinkage and elasticity of flowable composites and filled adhesives. Dent. Mater. 1999, 15, 128-137. [CrossRef]

7. Klee, J.E.; Schneider, C.; Hölter, D.; Burgath, A.; Frey, H.; Mülhaupt, R. Hyperbranched polyesters and their application in dental composites: Monomers for low shrinking composites. Polym. Adv. Technol. 2001, 12, 346-354. [CrossRef]

8. Schneider, L.F.J.; Cavalcante, L.M.; Silikas, N. Shrinkage Stresses Generated during Resin-Composite Applications: A Review. J. Dent. Biomech. 2010, 2010, 131630. [CrossRef]

9. Sun, X.; Li, Y.; Xiong, J.; Hu, X.; Chen, J. Shrinkage properties of a modified dental resin composites containing a novel spiro-orthocarbonate expanding monomer. Mater. Lett. 2011, 65, 3586-3589. [CrossRef]

10. Moon, E.J.; Lee, J.Y.; Kim, C.K.; Cho, B.H. Dental restorative composites containing 2,2-bis-[4-(2-hydroxy-3-methacryloyloxy propoxy) phenyl] propane derivatives and spiro orthocarbonates. J. Biomed. Mater. Res. Part B Appl. Biomater. 2005, 73B, 338-346. [CrossRef]

11. Reed, B.B.; Stansbury, J.W.; Antonucci, J.M. Ring-Opening Dental Resin Systems Based on Cyclic Acetals. In Polymers of Biological and Biomedical Significance; American Chemical Society: Washington, DC, USA, 1993; Volume 540, pp. 184-190. 
12. Catel, Y.; Fassler, P.; Fischer, U.; Gorsche, C.; Liska, R.; Schorpf, S.; Tauscher, S.; Moszner, N. Synthesis and polymerization of vinylcyclopropanes bearing urethane groups for the development of low-shrinkage composites. Eur. Polym. J. 2018, 98, $439-447$. [CrossRef]

13. Childress, K.K.; Alim, M.D.; Hernandez, J.J.; Stansbury, J.W.; Bowman, C.N. Additive manufacture of lightly crosslinked semicrystalline thiol-enes for enhanced mechanical performance. Polym. Chem. 2020, 11, 39-46. [CrossRef]

14. Podgórski, M.; Becka, E.; Claudino, M.; Flores, A.; Shah, P.K.; Stansbury, J.W.; Bowman, C.N. Ester-free thiol-ene dental restoratives-Part A: Resin development. Dent. Mater. 2015, 31, 1255-1262. [CrossRef]

15. Hoyle, C.E.; Bowman, C.N. Thiol-Ene Click Chemistry. Angew. Chem. Int. Ed. 2010, 49, 1540-1573. [CrossRef]

16. Carioscia, J.A.; Lu, H.; Stanbury, J.W.; Bowman, C.N. Thiol-ene oligomers as dental restorative materials. Dent. Mater. 2005, 21, 1137-1143. [CrossRef]

17. Cramer, N.B.; Couch, C.L.; Schreck, K.M.; Boulden, J.E.; Wydra, R.; Stansbury, J.W.; Bowman, C.N. Properties of methacrylatethiol-ene formulations as dental restorative materials. Dent. Mater. 2010, 26, 799-806. [CrossRef]

18. Cramer, N.B.; Couch, C.L.; Schreck, K.M.; Carioscia, J.A.; Boulden, J.E.; Stansbury, J.W.; Bowman, C.N. Investigation of thiol-ene and thiol-ene-methacrylate based resins as dental restorative materials. Dent. Mater. 2010, 26, 21-28. [CrossRef]

19. Podgorski, M.; Becka, E.; Claudino, M.; Flores, A.; Shah, P.K.; Stansbury, J.W.; Bowman, C.N. Ester-free thiol-ene dental restoratives-Part B: Composite development. Dent. Mater. 2015, 31, 1263-1270. [CrossRef]

20. Fu, W.; Wang, L.; He, J.W. Evaluation of mechanical properties and shrinkage stress of thiol-ene-methacrylate dental composites with synthesized fluorinated allyl ether. J. Mech. Behav. Biomed. Mater. 2019, 95, 53-59. [CrossRef]

21. Zheng, Y.C.; Li, S.P.; Weng, Z.L.; Gao, C. Hyperbranched polymers: Advances from synthesis to applications. Chem. Soc. Rev. 2015, 44, 4091-4130. [CrossRef]

22. Wan, Q.C.; Schricker, S.R.; Culbertson, B.M. Methacryloyl derivitized hyperbranched polyester. 2. Photo-polymerization and properties for dental resin systems. J. Macromol. Sci. A 2000, 37, 1317-1331. [CrossRef]

23. Dewaele, M.; Leprince, J.G.; Fallais, I.; Devaux, J.; Leloup, G. Benefits and Limitations of Adding Hyperbranched Polymers to Dental Resins. J. Dent. Res. 2012, 91, 1178-1183. [CrossRef] [PubMed]

24. Yu, B.; Liu, F.; He, J. Preparation of low shrinkage methacrylate-based resin system without Bisphenol A structure by using a synthesized dendritic macromer (G-IEMA). J. Mech. Behav. Biomed. Mater. 2014, 35, 1-8. [CrossRef] [PubMed]

25. Vidotti, H.A.; Manso, A.P.; Leung, V.; do Valle, A.L.; Ko, F.; Carvalho, R.M. Flexural properties of experimental nanofiber reinforced composite are affected by resin composition and nanofiber/resin ratio. Dent. Mater. 2015, 31, 1132-1141. [CrossRef]

26. Lu, H.; Carioscia, J.A.; Stansbury, J.W.; Bowman, C.N. Investigations of step-growth thiol-ene polymerizations for novel dental restoratives. Dent. Mater. 2005, 21, 1129-1136. [CrossRef]

27. Örtengren, U.; Wellendorf, H.; Karlsson, S.; Ruyter, I.E. Water sorption and solubility of dental composites and identification of monomers released in an aqueous environment. J. Oral Rehabil. 2001, 28, 1106-1115. [CrossRef]

28. Senyurt, A.F.; Wei, H.; Hoyle, C.E.; Piland, S.G.; Gould, T.E. Ternary Thiol-Ene/Acrylate Photopolymers: Effect of Acrylate Structure on Mechanical Properties. Macromolecules 2007, 40, 4901-4909. [CrossRef]

29. Li, Q.; Zhou, H.; Hoyle, C.E. The effect of thiol and ene structures on thiol-ene networks: Photopolymerization, physical, mechanical and optical properties. Polymer 2009, 50, 2237-2245. [CrossRef]

30. Beigi, S.; Yeganeh, H.; Atai, M. Evaluation of fracture toughness and mechanical properties of ternary thiol-ene-methacrylate systems as resin matrix for dental restorative composites. Dent. Mater. 2013, 29, 777-787. [CrossRef]

31. Lee, T.Y.; Carioscia, J.; Smith, Z.; Bowman, C.N. Thiol-allyl ether-methacrylate ternary systems. Evolution mechanism of polymerization-induced shrinkage stress and mechanical properties. Macromolecules 2007, 40, 1473-1479. [CrossRef]

32. Carioscia, J.A.; Stansbury, J.W.; Bowman, C.N. Evaluation and control of thiol-ene/thiol-epoxy hybrid networks. Polymer 2007, 48, 1526-1532. [CrossRef]

33. Zhang, J.; Li, L.; Guo, R.; Zhou, H.; Li, Z.; Chen, G.; Zhou, Z.; Li, Q. Preparation of novel UV-cured methacrylate hybrid materials with high thermal stability via thiol-ene photopolymerization. J. Mater. Sci. 2019, 54, 5877-5897. [CrossRef]

34. Malacarne, J.; Carvalho, R.M.; de Goes, M.F.; Svizero, N.; Pashley, D.H.; Tay, F.R.; Yiu, C.K.; Carrilho, M.R.d.O. Water sorption/solubility of dental adhesive resins. Dent. Mater. 2006, 22, 973-980. [CrossRef]

35. Wang, X.; Huyang, G.; Palagummi, S.V.; Liu, X.; Skrtic, D.; Beauchamp, C.; Bowen, R.; Sun, J. High performance dental resin composites with hydrolytically stable monomers. Dent. Mater. 2018, 34, 228-237. [CrossRef]

36. Zhang, Y.; Miao, H.; Shi, W. Photopolymerization behavior and properties of highly branched polyester acrylate containing thioether linkage used for UV curing coatings. Prog. Org. Coat. 2011, 71, 48-55. [CrossRef]

37. Fonseca, A.S.Q.S.; Labruna Moreira, A.D.; de Albuquerque, P.P.A.C.; de Menezes, L.R.; Pfeifer, C.S.; Schneider, L.F.J. Effect of monomer type on the CC degree of conversion, water sorption and solubility, and color stability of model dental composites. Dent. Mater. 2017, 33, 394-401. [CrossRef]

38. Sideridou, I.; Tserki, V.; Papanastasiou, G. Study of water sorption, solubility and modulus of elasticity of light-cured dimethacrylate-based dental resins. Biomaterials 2003, 24, 655-665. [CrossRef] 